\title{
As relativas não preposicionadas no português falado em Feira de Santana - BA
}

\author{
The non-prepositional relative \\ clauses in the spoken portuguese \\ in Feira de Santana - BA
}

\author{
Jéssica Carneiro da Silva ${ }^{1}$ \\ https://orcid.org/0000-0003-2050-2780 \\ Silvana Silva de Farias Araújo ${ }^{2}$ \\ https://orcid.org/0000-0001-5561-3179 \\ Cristina Figueiredo ${ }^{3}$ \\ https://orcid.org/0000-0003-0665-9597
}

Resumo: Este artigo apresenta o estudo sociolinguístico do uso das estratégias de relativização em termos não preposicionados em 24 entrevistas referentes as normas culta e popular do português falado em Feira de Santana-BA. Objetivou-se analisar as relativas não preposicionadas e o uso da anáfora pronominal em tais construções, dialogando com Mollica (2003), Gomes (2003) e Duarte (2003). Fixou-se como variável dependente a relativização de termos não preposicionados: i) relativas com lacuna e ii) relativa com pronome anafórico. Foram controladas variáveis linguísticas e extralinguísticas, com o intuito de compreender os encaixamentos linguístico e social dos fenômenos. Os resultados revelaram uso quase exclusivo do que e baixa frequência da anáfora nas relativas das amostras culta e popular.

Palavras-chave: Sociolinguística; Relativas não preposicionadas; Anáfora pronominal; Português feirense.

\footnotetext{
${ }^{1}$ Universidade Federal da Bahia. E-mail: jessxcs@gmail.com

${ }^{2}$ Universidade Estadual de Feira de Santana. E-mail: silvana.uefs.2014@gmail.com

${ }^{3}$ Universidade Federal da Bahia. E-mail: macrisfig@uol.com.br
} 
Abstract: This paper presents the sociolinguistic study of the use of strategies of relativization in terms not prepositioned in 24 interviews referring to the cult and popular norms of spoken Portuguese in Feira de Santana-BA. The objective was to analyze the non-prepositional relative and the use of pronominal anaphora in such constructions, dialoguing with Mollica (2003), Gomes (2003) and Duarte (2003). The dependent variable was the relativization of non-prepositional terms: i) relative to gap and ii) relative to anaphoric pronoun. It controlled the linguistic and extralinguistic variables in order to understand the linguistic and social constraints of the phenomena. The results revealed almost exclusive use of "que" and low frequency of anaphora in the relative of cultured and popular samples.

Keywords: Sociolinguistics; Non-prepositional relative clauses; Pronominal anaphora; Feirense portuguese.

\section{Introdução}

O uso variável das orações relativas tem sido com frequência objeto de investigação em diversos estudos, seja do português escrito, seja do português falado (TARALLO, 1993; BURGOS, 2003; RIBEIRO, 2009, entre outros). Nesses trabalhos, é focalizada a variação entre as estratégias de relativização e atesta-se o aumento da relativa cortadora em contraposição com a diminuição do uso da relativa pied piping, além do estatuto do relativo que como pronome relativo ou complementizador e os mecanismos de referência provenientes das conexões intersentenciais, com a presença da anáfora nas construções não preposicionadas e preposicionadas.

Além das relativas consideradas padrão - não preposicionadas e preposicionadas como em (1a) e (2a), encontram-se no português brasileiro (PB) duas formas inovadoras, consideradas não padrão: são as relativas com pronome anafórico, como em (1b), variando com (1a), e as relativas cortadoras, como em (2b), variando com (2a). Para identificação das relativas padrão - nomenclatura cunhada por Tarallo (1993, p. 78-79), que têm uma lacuna na posição original do sintagma relativizado, são denominadas como relativa com lacuna a estratégia padrão não preposicionada, como em (1a), e como relativa pied piping a estratégia padrão preposicionada como em (2a).

(1) a. O doce [que comprei na padaria ontem] estava muito gostoso. (relativa com lacuna não preposicionada)

b. O doce [que comprei ele na padaria ontem] estava muito gostoso. (relativa com pronome anafórico)

(2) a. Esse é o vestido [com que saí ontem]. (relativa preposicionada ou pied piping) 
b. Esse é o vestido [Ø que saí ontem]. (relativa cortadora)

Este estudo foi desenvolvido no âmbito da Sociolinguística Variacionista (LABOV, 1972 [1968]) e teve como objetivos descrever e analisar nas normas culta e popular do português urbano feirense as estratégias de relativização de termos não preposicionados - relativas com lacuna, como em (1a), e relativas com pronome anafórico, como em (1b) - a fim de identificar o comportamento (socio)linguístico dessas construções e da anáfora pronominal.

Este texto debruça-se sobre as hipóteses de que o português brasileiro tenha sofrido uma mudança no sistema sintático com a fixação da relativa cortadora (TARALLO, 1983, p. 203) e que a suposta mudança de um tipo de estratégia anafórica esteja relacionada a perda de preposições (GOMES, 1996, p. 82) e ao aumento do preenchimento do sujeito (DUARTE, 1995, p. 117). Aventam-se tais hipóteses para explicar o encaixamento linguístico ou estrutural do fenômeno.

No âmbito do encaixamento social, busca-se confirmar o que foi sinalizado por Corrêa (1998, p. 95), observando se o uso da anáfora é inibido pela escolaridade e, de acordo com o paradoxo do gênero proposto por Labov (2001, p. 278), acredita-se que as mulheres façam uso mais frequente da anáfora do que os homens, já que em mudanças sem consciência social (from below), as mulheres usam com maior frequência formas inovadoras do que os homens.

Assim, tem-se como objetivos descrever as estratégias de relativização não preposicionadas e o uso da anáfora pronominal, analisar seu comportamento variável comparando-se dois polos de fala: o da norma culta e o da norma popular do português falado em Feira de Santana, buscando, também, responder se o município feirense se encontra linguisticamente polarizado (LUCCHESI, 2015b, p. 90) no que diz respeito ao uso da anáfora pronominal.

Para tanto, foram selecionadas nas entrevistas as ocorrências de relativas desenvolvidas, isto é, aquelas introduzidas por um pronome relativo, as quais foram codificadas segundo a variável dependente, que diz respeito à relativização de termos não preposicionados. Foram controladas variáveis linguísticas e sociais com o intuito de comprovar ou refutar as hipóteses aventadas, tais variáveis são detalhadas posteriormente.

Este artigo está assim organizado: na seção I, faz-se uma apresentação do tema, descrevendo as estratégias de relativização não preposicionadas encontradas no PB e do uso da anáfora nessas construções, perfazendo uma breve revisão da literatura; na seção II, tecem-se considerações sobre os pressupostos teórico-metodológicos adotados neste trabalho; na seção 
III, são apresentados os resultados obtidos na análise variacionista e, por fim, são apresentadas as considerações finais

\section{$1 \mathrm{O}$ fenômeno: as estratégias de relativização}

As orações relativas, denominadas pela tradição gramatical de orações subordinadas adjetivas, modificam um nome, dando origem a um constituinte complexo ${ }^{4}$ que integra a oração principal ou matriz. No exemplo em (3), a seguir, a oração subordinada destacada modifica o núcleo nominal móveis, restringindo-o. E o constituinte complexo formado exerce a função de sujeito na oração principal ou matriz, cujo núcleo predicador é chegam.

(3) Os móveis [que comprei _ chegam amanhã].

Essa construção chama-se relativa por ser introduzida pelo pronome relativo que, no exemplo em (3), cujas funções são: i) introduzir a oração encaixada, estabelecendo coesão sequencial entre duas orações, e ii) retomar o nome que o antecede, estabelecendo coesão referencial $^{5}$. Além disso, o pronome relativo exerce, na oração que introduz, a função sintática do termo relativizado. Em (03), o relativo que exerce a função sintática de objeto direto, conforme evidencia a divisão da sentença em duas orações em (4):

(4) Os móveis chegam amanhã. / Eu comprei [os móveis] oD.

A lacuna na posição de objeto direto do verbo comprar em (3) visa a demonstrar que o objeto direto foi deslocado de sua posição de origem para a posição inicial da oração encaixada, devido à necessidade de retomar o núcleo nominal da oração matriz e estabelecer a coesão entre as orações. Quando o pronome relativo exerce funções sintáticas que requerem preposição, o pronome relativo deve também ser precedido de preposição, deixando uma lacuna na posição de origem do sintagma preposicional relativizado, como no exemplo em (5).

${ }^{4}$ Sintagma constituído por um núcleo nominal modificado ou complementado por uma oração subordinada.

${ }^{5}$ As orações relativas podem ocorrer sem antecedente. Elas são chamadas de relativas livres ou relativas sem cabeça. Neste trabalho, não se tratou desse tipo de relativa. Será focalizado em trabalhos posteriores. 
A esse tipo de relativas, Tarallo (1993, p. 78) denominou de relativa pied piping, isto é, uma relativa preposicionada ${ }^{6}$.

(5) Todos compraram o livro [a que referi __ durante a palestra].

Tendo em vista a lacuna na posição de origem do sintagma relativizado, as orações relativas consideradas padrão, principalmente em trabalhos de cunho gerativistas (TARALLO, 1993, p. 69-100; RIBEIRO, 2009, p. 185-208; RIBEIRO E FIGUEIREDO, 2009, p. 208-240), são chamadas de relativas com lacuna. As orações relativas, segundo a tradição gramatical, são introduzidas pelos pronomes relativos elencados a seguir:
a. variáveis: o qual, cujo
b. invariáveis: que, quem, onde, quando e como

Os relativos, como dito anteriormente, exercem função sintática na oração principal: funções não preposicionadas, sujeito e objeto direto, principalmente; e funções preposicionadas, objeto indireto, complemento oblíquo, adjunto adverbial, agente da passiva.

Sobre as relativas é também interessante registrar que elas modificam o núcleo nominal, restringindo-o ou especificando-o, como em (7), ou acrescentando uma informação a mais ao termo a que se refere, como em (8).

(6) O diretor da escola fará uma palestra sobre problemas [que têm atingido os adolescentes].

(7) O diretor da escola fará uma palestra sobre o alcoolismo, [que tem atingido os adolescentes].

Em (6), a oração subordinada, destacada em itálico, restringe o sentido do termo problemas, que semanticamente é [-específico]. Dessa forma, a oração relativa é essencial à referencialidade desse nome. Esse tipo de oração é denominado de relativa restritiva. $\mathrm{Em}$ (7), a oração subordinada em destaque detalha e amplia as informações sobre o núcleo nominal a que se refere, alcoolismo, visto que se trata de um problema conhecido por todos, é, portanto,

${ }^{6}$ É necessário evidenciar que esse tipo de construção não é o foco deste estudo, já que a análise contemplou as relativas não preposicionadas. 
semanticamente [+específico]. Nesse caso, a oração relativa é desnecessária à identificação desse nome. Chama-se de relativa explicativa a oração subordinada que tem essa função.

Análises do PB demonstram que as estratégias indicadas como padrão pela tradição gramatical variam com estruturas consideradas não padrão. Tarallo (1983, p. 203-211; 1993, p. 78-79), que realiza uma pesquisa de cunho diacrônico sobre as estratégias de relativização, diagnostica que, no PB, há três estratégias de relativização: i) relativa padrão ou relativa com lacuna, não preposicionadas e preposicionadas, como nos exemplos em (3) e em (5), respectivamente; ii) relativa com pronome lembrete ou anáfora pronominal, ou com a lacuna preenchida, como no exemplo em (8); e iii) relativa cortadora, como no exemplo em (9).

(08) Esse é o rapaz [que encontrei ele no restaurante com sua mãe].

Em (8), de acordo com a tradição gramatical, o pronome relativo retoma o núcleo nominal rapaz e exerce a função de objeto direto na oração subordinada. Porém, na posição de objeto direto, verifica-se a presença do pronome pessoal ele, que, por retomar mais uma vez o núcleo nominal da sentença matriz, é considerado um pronome lembrete ou resumptivo. Pronomes lembretes também ocorrem em relativas pied piping. As estratégias sem lacuna são consideradas não padrão pela tradição gramatical e, de acordo com Tarallo (1983, p. 220), são estigmatizadas socialmente.

O terceiro tipo de relativas encontrado no PB, a relativa cortadora, varia particularmente com as relativas pied piping e consiste na não realização da preposição diante do pronome relativo - sendo possível também a colocação da anáfora - como se vê no exemplo em (9), a seguir.

(9) Todos compraram o livro [que referi durante a palestra].

Na sentença em (10), o termo relativizado é um complemento oblíquo que requer uma preposição, referi-me ao livro, portanto a preposição, de acordo com o que prescreve a tradição gramatical, deveria preceder o relativo que. Embora considerada não padrão, essa estratégia não é estigmatizada e, talvez, por esse motivo, no PB, vem se tornando mais frequente que a variante padrão em que a preposição é realizada (TARALLO, 1993, p. 69-100; BURGOS, 2003, p. 95119; RIBEIRO, 2009, p.185-208).

Os resultados dos estudos diacrônicos de Tarallo (1993, p. 88) revelaram, considerando as sincronias (1725, 1775, 1825 e 1880), a ascensão da variante cortadora com o passar do tempo $(0,9 \%, 4,0 \%, 7,5 \%, 59,5 \%)$, e a queda das relativas pied piping $(89,2 \%, 88,1 \%, 91,3 \%$, 
35,4\%), apontando para um processo de mudança, ou seja, de substituição da estratégia padrão pela estratégia não padrão. As relativas com pronome lembrete, no corpus analisado pelo autor, mantêm um comportamento equilibrado, exceto na terceira sincronia (9,9\%, 7,9\%, 1,3\%, 5,1\%) e apresentam um comportamento marginal no sistema sintático do PB. Os resultados de Tarallo (1993, p. 80), quanto à variação entre a estratégia com lacuna e a com pronome lembrete nas estruturas de relativização de sujeito e de objeto direto, funções que não requerem preposição, apontam para a predominância das estratégias com lacuna em detrimento da estratégia com pronome lembrete. Quando o sujeito é relativizado, verificam-se $89,7 \%$ de relativas com lacuna e, quando é o objeto direto relativizado, 97,4\%.

Burgos (2003, p. 78-115) também realizou uma pesquisa empírica sobre realização variável das relativas não padrão no português rural afro-brasileiro, considerando que o contato entre línguas ocorrido durante o período de colonização no Brasil teria interferido na aquisição do português. Seu corpus se constituiu a partir de amostras de fala da comunidade Helvécia, localizada no município de Nova Viçosa, estado da Bahia. Os dados de Burgos (2003) totalizaram 569 orações relativas. Chama atenção o fato de o autor não ter encontrado nenhuma ocorrência relativa pied piping e apenas 18 relativas com pronome lembrete. Em seu corpus, o autor computou 185 ocorrências de relativa cortadora, totalizando 32\% dos dados.

Observando o comportamento dos complementadores e dos pronomes relativos em diversas línguas naturais e comparando com o comportamento do que nas comunidades rurais afro-brasileiras, Ribeiro (2009, p. 194) propõe que, devido ao processo de transmissão linguística irregular como consequência do contato do português com as línguas africanas, esse morfema teria passado por um processo de mudança em relação ao português europeu. Para os contextos em que esse morfema tem o status de pronome relativo para o PE, Ribeiro (2009, p. 192) afirma que, no dialeto do português rural afro-brasileiro, esse morfema é um complementador.

Ribeiro e Figueiredo (2009, p. 208-240) analisam o português escrito no século XIX por africanos alforriados a fim de verificar se, no processo de aquisição de segunda língua, ocorre um comportamento semelhante ao observado no PB, presença das estratégias com pronome lembrete e da cortadora. Os resultados, porém, demonstraram que o português desses africanos reflete a gramática portuguesa. Dentre as 17 ocorrências de relativa em funções preposicionadas encontradas no corpus, verificou-se apenas 01 de relativa cortadora.

Na seção seguinte, detalha-se o quadro teórico-metodológico utilizado para a obtenção dos resultados. 


\section{Pressupostos teórico-metodológicos}

A Sociolinguística Quantitativa (LABOV, 1968[1972]) postula a impossibilidade de se perceber a mudança linguística fora da comunidade de fala. Para essa teoria, a mudança deve ser compreendida considerando-se a vida social da comunidade de fala em que são produzidos os dados de fala, pois a língua sofre pressões e influências sociais constantemente. Afirma-se, pois, que a mudança não é proveniente de uma deriva natural, mas resultante da variação inerente na comunidade de fala, motivada pelo encaixamento linguístico e social das variantes linguísticas.

Além de propor a contextualização da mudança linguística na sociedade, a Sociolinguística Variacionista propõe que, para analisar a variação e/ou mudança linguística, é fundamental considerar explicações linguísticas e extralinguísticas. Ou seja, é preciso que se investiguem os fatores que condicionam a escolha do falante dentre as variantes em competição, a partir da observação dos padrões coletivos de comportamentos linguísticos numa dada comunidade de fala, a qual é interpelada por fatores linguísticos e sociais. Dessa forma, o estudo de qualquer fenômeno linguístico deve considerar o contexto sócio-histórico da comunidade de fala, pois é numa comunidade de fala que se encontra "a síntese do geográfico com o social" (CARDOSO, 2010, p. 12).

Segundo Almeida (2012, s/p.), inicialmente, o contato linguístico em Feira de Santana ocorreu entre portugueses de diferentes localidades, paulistas, crioulos, descendentes de índios, e, atualmente, ocorre entre os dialetos nordestinos e, em menor escala, com outros dialetos. Por essas características peculiares, o município circunscreve-se como uma comunidade de fala singular, com a qual é possível destacar o entrecruzamento do contato rural com o urbano, já que este município agrega falares de diversas localidades da Bahia e do Brasil.

Por possuir esse entrecruzamento do contato de indivíduos de áreas rurais com os de áreas urbanas na sua formação sócio-histórica, pode-se observar que, em Feira de Santana, há um intenso contato entre as normas popular e culta do português brasileiro, permitindo assim apoiar as ideias de Mattos e Silva (2004, p. 64) de que há uma provável aproximação das normas popular e culta do PB, ou seja, tais normas podem estar em processo de aproximação com influências mútuas, já que, a partir do século XX, ocorreram mudanças profundas e contínuas no Brasil, inferência proposta por Lucchesi (2001, p. 105). Além disso, a possível aproximação das normas culta e popular no português feirense, pode dar indícios de que o uso da anáfora é inibido pela escolaridade, como apontou Corrêa (1989, p. 95). 
Assim, com a descrição e a análise das estratégias de relativização não preposicionadas e do uso da anáfora pronominal, tem-se o intuito de analisar também seu comportamento variável, comparando-se dois polos de fala: o da norma culta e o da norma popular do português falado em Feira de Santana-BA, buscando responder se o município feirense se encontra linguisticamente polarizado, no que diz respeito a essa variável (LUCCHESI, 2015, p. 90) ou se há uma possível aproximação dessas normas (MATTOS E SILVA, 2004, p. 64), no que diz respeito ao uso das relativas não preposicionadas com ou sem o uso da anáfora.

\subsection{A amostra investigada}

As entrevistas analisadas pertencem ao acervo do projeto $A$ língua portuguesa do semiárido baiano - Fase 3: amostras da língua falada em Feira de Santana-Ba, sediado no Núcleo de Estudos da Língua Portuguesa (NELP) ${ }^{7}$, do Departamento de Letras e Artes da Universidade Estadual de Feira de Santana. Os inquéritos foram gravados de 2008 a 2013 e os informantes foram selecionados de acordo com as variáveis sociais registradas no Quadro 1, a seguir (ARAUJO; ALMEIDA, 2014, p. 35):

Quadro 1 - Fatores socioculturais utilizados na constituição da amostra do Projeto de pesquisa $A$ língua Portuguesa no Semiárido Baiano - Fase 3

\begin{tabular}{|l|l|}
\hline \multicolumn{2}{|c|}{ FATORES SOCIOCULTURAIS } \\
\hline \multirow{2}{*}{ Sexo } & Masculino \\
\cline { 2 - 2 } & Feminino \\
\hline \multirow{3}{*}{ Faixa etária } & Faixa I (25-35 anos) \\
\cline { 2 - 2 } & Faixa II (45-55 anos) \\
\cline { 2 - 2 } & Faixa III (a partir de 65 anos) \\
\hline \multirow{3}{*}{ Escolaridade } & Baixa ou inexistente \\
\cline { 2 - 2 } & Ensino Médio completo \\
\cline { 2 - 2 } & Ensino superior completo e/ou pós-graduação \\
\hline
\end{tabular}

Fonte: elaborado pela autora.

\footnotetext{
${ }^{7}$ Núcleo de Estudos da Língua Portuguesa (NELP), disponível em: <http://www2.uefs.br/nelp/projetos.htm>.
} 
Para a realização desse estudo, foram analisadas amostras de fala de 24 informantes, 12 que compõem a amostra do português popular e 12 que constituem a amostra do português culto $^{8}$ de Feira de Santana-BA, distribuídos em três faixas etárias.

Após o levantamento dos dados, considerando as restrições estabelecidas ${ }^{9}$, foi fixada a variável dependente deste estudo: relativa com lacuna, como em (10), versus relativa com lembrete ou pronome anafórico, como exemplificada em (11).

(10) Então nós temos um público [que vem para rua ver o bando]. [INF12.C.F3.S.F] ${ }^{10}$

(11) Eu tenho um sobrinho emprestado, sobrinho do meu namorado [que ele mexe no computador mais do que eu]. [INF04.C.F1.T.F]

Para compreender o encaixamento linguístico, as variáveis linguísticas explanatórias consideradas para a análise estão distribuídas no Quadro 2, a seguir.

Quadro 2 - Variáveis linguísticas controladas

\begin{tabular}{|l|l|}
\hline \multicolumn{1}{|c|}{ VARIÁVEIS LINGUíSTICAS } & \multicolumn{1}{c|}{ FATORES } \\
\hline Tipo de pronome relativo & $\begin{array}{l}\text { Que; quem; o/os e a/as qual(is); cujo(a); onde; quanto; } \\
\text { quando; como. }\end{array}$ \\
\hline Função sintática do pronome relativo & $\begin{array}{l}\text { Sujeito; objeto direto; objeto indireto; objeto oblíquo; } \\
\text { complemento locativo; adjuntos adverbiais; genitivo; } \\
\text { agente da passiva; adjuntos adnominais; complemento } \\
\text { nominal; predicativo; aposto; quantificador; objeto } \\
\text { topicalizado. }\end{array}$ \\
\hline Função sintática do antecedente & $\begin{array}{l}\text { Sujeito; objeto direto; objeto indireto; objeto oblíquo; } \\
\text { complemento locativo; adjuntos adverbiais; genitivo; } \\
\text { agente da passiva; adjuntos adnominais; complemento } \\
\text { nominal; predicativo; aposto; quantificador; objeto } \\
\text { topicalizado. }\end{array}$ \\
\hline Natureza da oração & Restritiva; explicativa. \\
\hline Natureza semântica do antecedente & [+ animado]; [- animado]. \\
\hline $\begin{array}{l}\text { Valor semântico do conectivo } \\
\text { oracional }\end{array}$ & Pessoa; causa; lugar; modo; coisa; quantidade; tempo. \\
\hline
\end{tabular}

Fonte: elaborado pela autora

${ }^{8}$ Utiliza-se o conceito da bipolarização de normas do português brasileiro, com base em Lucchesi (1994, p. $65 ; 2001$, p. 34,2015 , p. 90, entre outros).

${ }^{9}$ Não foram consideradas as relativas livres, as reduzidas e as construções de clivagem.

${ }^{10}$ Os códigos que seguem os exemplos possuem a finalidade de identificar o informante. Exemplo: [INF02P.L.F1.F] = INF02 para Informante 02; $P$ para norma popular; $L$ para o nome do(a) informante; $F 1$ para Faixa 1; e F para sexo feminino. 
Quanto ao encaixamento social, o estudo controlou as seguintes variáveis extralinguísticas: o sexo, a faixa etária e a escolaridade do informante, como foi destacado no Quadro 1. Finalizada a fase do levantamento e a codificação das ocorrências, os dados foram quantificados pelo programa computacional Goldvarb X (2005). Na próxima seção, é apresentada a análise quantitativa e qualitativa dos resultados encontrados após as análises realizadas.

\section{Apresentação e discussão dos resultados}

\begin{tabular}{|l|l|}
\hline \multicolumn{1}{|c|}{ VARIÁVEIS LINGUÍSTICAS } & \multicolumn{1}{c|}{ FATORES } \\
\hline Tipo de pronome relativo & $\begin{array}{l}\text { Que; quem; o/os e a/as qual(is); cujo(a); onde; quanto; } \\
\text { quando; como. }\end{array}$ \\
\hline Função sintática do pronome relativo & $\begin{array}{l}\text { Sujeito; objeto direto; objeto indireto; objeto oblíquo; } \\
\text { complemento locativo; adjuntos adverbiais; genitivo; } \\
\text { agente da passiva; adjuntos adnominais; complemento } \\
\text { nominal; predicativo; aposto; quantificador; objeto } \\
\text { topicalizado. }\end{array}$ \\
\hline Função sintática do antecedente & $\begin{array}{l}\text { Sujeito; objeto direto; objeto indireto; objeto oblíquo; } \\
\text { complemento locativo; adjuntos adverbiais; genitivo; } \\
\text { agente da passiva; adjuntos adnominais; complemento } \\
\text { nominal; predicativo; aposto; quantificador; objeto } \\
\text { topicalizado. }\end{array}$ \\
\hline Natureza da oração & Restritiva; explicativa. \\
\hline Natureza semântica do antecedente & [+ animado]; [- animado]. \\
\hline $\begin{array}{l}\text { Valor semântico do conectivo } \\
\text { oracional }\end{array}$ & Pessoa; causa; lugar; modo; coisa; quantidade; tempo. \\
\hline
\end{tabular}

Nesta seção, são apresentados os resultados da quantificação das relativas não preposicionadas nas normas culta e popular do português falado em Feira de Santana-BA, sendo dividida em duas análises: 1) análise da distribuição geral dos resultados, observando o comportamento das relativas com lacuna e das relativas com pronome anafórico, as funções sintáticas relativizadas pelo pronome relativo e em quais posições a anáfora ocorre, verificando de forma geral o seu processamento nas relativas; 2) análise das rodadas binárias, estabelecendo como aplicação de regra a realização da anáfora pronominal nas relativas não preposicionadas.

A quantificação das relativas não preposicionadas nas duas normas investigadas (culta e popular) do português falado em Feira de Santana-BA totalizou 932 orações. Dessas 932 ocorrências, 923 são relativas introduzidas pelo pronome relativo que, resultando em um 
percentual de 99\%, o que demonstra um uso exclusivo deste relativo. Do total de 932 relativas não preposicionadas, 919 são de relativas com lacuna, referentes à 98\% da amostra e apenas 13 são de relativas com pronome anafórico, $2 \%$ dos dados, como pode-se visualizar com a distribuição geral dos resultados referentes às estratégias não preposicionadas, na Tabela 1.

Tabela 1 - Distribuição geral das estratégias não preposicionadas encontradas no português falado em Feira de Santana-BA: culto e popular

\section{ESTRATÉGIAS DE RELATIVIZAÇÃO \\ OC./TOTAL \\ FREQUÊNCIA}

\begin{tabular}{lcc}
\hline Com lacuna & $919 / 932$ & $98 \%$ \\
\hline Com pronome anafórico & $13 / 932$ & $2 \%$ \\
\hline
\end{tabular}

Observa-se que as relativas com lacuna estão distribuídas em maior número do que as relativas com lembrete ou com anáfora pronominal no português falado em Feira de SantanaBA, corroborando o que já foi atestado em trabalhos realizados sobre o tema (TARALLO, 1993, p. 69-100; BURGOS, 2003, p. 115; LUCCHESI, 2015a, 77-119; RIBEIRO E FIGUEIREDO, 2009, p. 208-240; OLIVEIRA E RIBEIRO, 2015, p.149-173). A Tabela 2, a seguir, distribui as estratégias não preposicionadas separando-se a norma culta e a norma popular.

Tabela 2 - Distribuição das estratégias não preposicionadas nas normas culta e popular do português falado em Feira de Santana-BA

\begin{tabular}{l|c|c|c|c}
\hline \multirow{2}{*}{$\begin{array}{l}\text { ESTRATÉGIAS DE } \\
\text { RELATIVIZAÇÃO }\end{array}$} & Oc./Total & Frequência & Oc./Total & Frequência \\
\cline { 2 - 5 } & & $99 \%$ & $380 / 386$ & $99 \%$ \\
\hline Com lacuna & $539 / 546$ & & & \\
\hline Com pronome anafórico & $7 / 546$ & $1 \%$ & $6 / 386$ & $1 \%$ \\
\hline
\end{tabular}

A distribuição dos resultados separando-se a norma popular e a norma culta revela que as estratégias de relativização não preposicionadas possuem um comportamento similar, tanto no que diz respeito às relativas com lacuna quanto às relativas com lembrete ou anáfora pronominal. As relativas com lacuna resultaram em 539 ocorrências (99\%) e as relativas com lembrete em 7 ocorrências (1\%) do total de 546 relativas encontradas na norma culta. Na norma popular, o percentual é o mesmo, sendo que de 386 ocorrências, 380 são de relativas com 
lacuna e 6 são de relativas com lembrete. Ao observar os resultados das Tabelas 1 e 2, pode-se inferir que se houve polarização (LUCCHESI, 2015b, p. 90) na comunidade de fala investigada, hoje já está superada, pelo menos no que concerne ao uso das orações relativas não preposicionadas, pois há ocorrências da anáfora tanto na norma popular (6/13) quanto na norma culta $(7 / 13)$.

Acredita-se que o pouco uso da relativa com anáfora seja consequência da estigmatização que os falantes atribuem a esse tipo de construção, explicando o seu caráter marginal, como salientou Tarallo (1993, p. 88). O pouco uso da relativa com pronome anafórico pode ser resultado do problema da avaliação (WEINREICH, LABOV E HERZOG, 2006 [1968]) e só é possível chegar a tais conclusões com a condução de trabalhos futuros, realizando testes de avaliação e de percepção linguística.

A Tabela 3, a seguir, reúne os resultados da distribuição geral da variável função sintática do pronome relativo, cuja hipótese era a de que as relativas com lacuna seriam mais produzidas na posição de sujeito, assim como o uso da anáfora também estaria se concentrando no domínio sintático do sujeito nas chamadas relativas com lembrete.

Tabela 3 - Distribuição geral da variável função sintática do pronome relativo nas estratégias não preposicionadas nas normas culta e popular do português feirense

\begin{tabular}{l|cc|cc}
\hline \multirow{2}{*}{$\begin{array}{l}\text { FUNÇÃO SINTÁTICA DO } \\
\text { PRONOME RELATIVO }\end{array}$} & \multicolumn{2}{|c|}{ RELATIVA COM LACUNA } & \multicolumn{2}{c}{$\begin{array}{l}\text { RELATIVA COM PRONOME } \\
\text { ANAFÓRICO }\end{array}$} \\
\cline { 2 - 5 } & Oc./Total & Frequência & Oc./Total & Frequência \\
\hline Sujeito & $634 / 644$ & $98 \%$ & $10 / 644$ & $2 \%$ \\
\hline Objeto direto & $264 / 265$ & $99 \%$ & $1 / 265$ & $9 \%$ \\
\hline Adjuntos adverbiais & $21 / 23$ & $91 \%$ & $2 / 23$ & $2 \%$ \\
\hline TOTAL & $919 / 932$ & $98 \%$ & $13 / 932$ & $2 \%$ \\
\hline
\end{tabular}

Os resultados da Tabela 3 estão em consenso com os resultados de Mollica (2003, p. 123), ao considerar que o uso da anáfora "esteja de fato se concentrando no domínio sintático do sujeito", confirmando a hipótese aventada, ao menos no que diz respeito às estratégias de relativização, o que confirma que a realização da estratégia anafórica esteja relacionada à perda de preposições (GOMES, 2003, p. 81-96), direcionando a uma complementação direta e ao aumento do preenchimento do sujeito (DUARTE, 1995; 2003, p. 115-128). As posições mais relativizadas nas relativas com lacunas são as de sujeito, com 634 (98\%) do total de 644 ocorrências, e as de objeto direto, com 264 (99\%) do total de 265 ocorrências. 
Nas relativas com pronome anafórico, a posição mais relativizada é a de sujeito, já que nas 13 ocorrências de anáfora, 10 foram encontradas nessa posição, isto é, em $77 \%$ das ocorrências de relativa com anáfora, o que mais uma vez confirma a afirmação de Mollica (2003, p. 124) sobre o domínio sintático do sujeito na realização da anáfora. As posições em que ocorre a anáfora nas relativas não preposicionadas do português falado em Feira de Santana estão exemplificadas em (12), (13) e (14), a seguir.

(12) Teve uma colega minha [que ela é enfermeira], ela disse que já teve muitos casos desse lá. [INF04P.I.F1.F] (SUJEITO)

(13) Engraçado porque antigamente esse meu irmão, esse [que a diretora queria ele como bolsista], é porque ele era o mais estudioso. [INF02C.F1.W.M] (OBJETO DIRETO)

(14) Meu sonho é conhecer o Rio de Janeiro, a cidade [onde minha filha mora [n]ela], um dia eu vou em nome de Jesus! [INF08P.R.F2.F] (ADJUNTO ADVERBIAL)

Como o objetivo deste estudo é o de verificar o comportamento da anáfora pronominal das relativas não preposicionadas do português falado em Feira de Santana-BA, nesse segundo momento da análise, apresentam-se os resultados das rodadas binárias, estabelecendo como aplicação de regra a realização da anáfora pronominal nas estratégias de relativização não preposicionadas.

Para a obtenção do peso relativo, foram retirados todos os fatores que apresentavam casos categóricos, houve a resolução dos knockouts e de todas as variáveis consideradas singleton groups pelo GoldVarb X. O programa selecionou para aplicação da anáfora nas relativas não preposicionadas do português falado em Feira de Santana-BA três variáveis de ordem linguística e uma variável de ordem social: natureza da oração; natureza semântica do antecedente; valor semântico do conectivo oracional e sexo. Ao observar a seleção dessas variáveis, pode-se conjecturar que o uso da anáfora é um fenômeno tanto de ordem linguística quanto de ordem social, o que permite fazer inferências iniciais de como esse fenômeno tem se encaixado linguistica e socialmente no português brasileiro.

Inicialmente, foi aventada a hipótese de que a escolaridade inibiria o uso da anáfora, isto é, quanto mais escolarizado fosse o falante, menos uso da anáfora ele faria, contribuindo assim para a sua redução, de acordo com o que foi confirmado por Mollica (2003, p. 123) e 
Corrêa (1998, p. 133), porém a não seleção da variável escolaridade nas duas normas investigadas permite afirmar que esta variável não interfere o uso do pronome anafórico.

As seguintes tabelas distribuem os resultados das variáveis selecionadas pelo programa para a aplicação da anáfora nas relativas não preposicionadas das duas normas do português feirense, em que se visualizam os contextos favorecedores das relativas anafóricas. A Tabela 4, a seguir, reúne os resultados percentuais e pesos relativos das variáveis linguísticas selecionadas e, posteriormente a essa análise, na Tabela 5, está apresentado apenas o resultado da variável social sexo.

Tabela 4 - Distribuição das variáveis linguísticas selecionadas para a aplicação da anáfora nas relativas não preposicionadas em Feira de Santana-BA

\begin{tabular}{|c|c|c|c|c|}
\hline VARIÁVEIS & FATORES & OC./TOTAL & FREQUÊNCIA & PESO RELATIVO \\
\hline \multirow{2}{*}{$\begin{array}{l}\text { Natureza da } \\
\text { oração }\end{array}$} & Explicativa & $8 / 13$ & $62 \%$ & .99 \\
\hline & Restritiva & $5 / 13$ & $38 \%$ & .46 \\
\hline \multirow{2}{*}{$\begin{array}{l}\text { Natureza } \\
\text { semântica do } \\
\text { antecedente }\end{array}$} & [+ animado] & $10 / 13$ & $77 \%$ & .92 \\
\hline & [- animado] & $3 / 13$ & $23 \%$ & .11 \\
\hline \multirow{2}{*}{$\begin{array}{l}\text { Valor semântico } \\
\text { do conectivo } \\
\text { oracional }\end{array}$} & Pessoa & $10 / 13$ & $77 \%$ & .92 \\
\hline & Lugar & $3 / 13$ & $23 \%$ & .40 \\
\hline
\end{tabular}

A Tabela 4 delineia os contextos linguísticos que favorecem o uso da anáfora nas relativas não preposicionadas. Com a leitura da Tabela 4, infere-se que o encaixamento linguístico do uso da anáfora nas relativas não preposicionadas ocorre quando a oração relativa é explicativa, isto é, construções em que se verifica uma informação adicional sobre o referente; quando o referente é + animado; e, quando o valor semântico do conectivo oracional é de pessoa. A natureza semântica do antecedente + animado e o valor semântico de pessoa do conectivo oracional está em consonância com o predomínio da relativização na posição de sujeito, assim como nos resultados de Mollica (2003, p. 123). A Tabela 5, a seguir, expõe os resultados referentes ao encaixamento social do uso da anáfora nas estratégias de relativização. 
Tabela 5 - Distribuição da variável sexo, selecionada para a aplicação da anáfora nas relativas não preposicionadas em Feira de Santana-BA

\begin{tabular}{lccc}
\hline SEXO & OC./TOTAL & FREQUÊNCIA & $\begin{array}{c}\text { PESO } \\
\text { RELATIVO }\end{array}$ \\
\hline Masculino & $3 / 13$ & $23 \%$ & .31 \\
Feminino & $10 / 13$ & $77 \%$ & .69 \\
\hline
\end{tabular}

Os resultados da Tabela 5 permitem concluir que o encaixamento social da anáfora se encontra no domínio da variável sexo e que o sexo feminino favorece sua realização. Logo é possível visualizar que as mulheres feirenses lideram o uso da anáfora, já que obtiveram um peso relativo de .69 no uso das estratégias com anáfora pronominal. Em suma, das 13 ocorrências de relativa com anáfora, 10 foram realizadas por mulheres, totalizando um percentual de 77\%. Isso confirma o paradoxo do gênero postulado por Labov (2001, p. 278) e a hipótese aventada anteriormente, de que as mulheres lideram mudanças sem consciência social (linguistic change from below), em que há pouca estigmatização social, mesmo que estes resultados sejam apenas indícios de uma possível mudança.

\section{CONSIDERAÇÕES FINAIS}

A análise das relativas não preposicionadas e do uso da anáfora nessas construções totalizou 932 estratégias de relativização, nas quais o "que" é o pronome relativo mais usado, sendo que foi realizado em 923 ocorrências. A distribuição geral dos dados quantificou 919 ocorrências de relativas com lacuna, referentes à 98\% da amostra e apenas 13 são de relativas com pronome anafórico, $2 \%$ dos dados, isso confirma o predomínio da relativa com lacuna e da possível estigmatização da relativa com lembrete ou com pronome anafórico.

Ao distribuir separadamente os resultados na norma culta e da norma popular, foi possível considerar que o português falado em Feira de Santana não se encontra polarizado (LUCCHESI, 2015, p. 90), no que diz respeito ao uso das estratégias de relativização não preposicionadas e da anáfora pronominal, pois tanto a norma culta quanto a norma popular obtiveram 99\% de relativas com lacuna e 1\% de relativa com pronome anafórico. Das 546 ocorrências de relativas não preposicionadas na norma culta, 539 são de relativas com lacuna 
e apenas 7 de relativas com lembrete. Das 386 estratégias de relativização não preposicionadas na norma popular, 380 são de relativas com lacuna e 6 são de relativas com lembrete.

Quanto às funções sintáticas relativizadas nas duas normas investigadas, as posições mais relativizadas nas relativas com lacunas foram as de sujeito, com 634 (98\%) do total de 644 ocorrências, e as de objeto direto, com 264 (99\%) do total de 265 ocorrências. Nas relativas com pronome anafórico, 10 das 13 ocorrências foram relativizadas na posição de sujeito, isto é, em $77 \%$ das ocorrências de relativa com anáfora, o que confirma a afirmação de Mollica (2003, p. 123) sobre o domínio sintático do sujeito na realização da anáfora.

Com as rodadas binárias, pôde-se destacar que as variáveis linguísticas que favoreceram o uso da anáfora nas relativas encontradas no português feirense foram: a natureza da oração; a natureza semântica do antecedente; e o valor semântico do conectivo oracional. A variável social que favoreceu a realização da anáfora foi a variável sexo.

Os resultados encontrados confirmaram que o encaixamento linguístico da anáfora nas relativas está de fato se concentrando no domínio sintático do sujeito (MOLLICA, 2003, p. 123), devido também ao aumento do preenchimento do sujeito (DUARTE, 2003, p. 115); o uso semicategórico do pronome relativo "que" confirma a hipótese de que a realização da estratégia anafórica esteja relacionada à perda de preposições (GOMES, 1996, p. 85), já que a substituição da estratégia pied piping pela cortadora se concretizou no português brasileiro (TARALLO, 1983, p. 203; RIBEIRO, 2009, 185-208; SILVA, 2018, p. 219-230; entre outros). Este fato direciona a uma complementação direta. Além disso, outros três fatores linguísticos favoreceram o uso da anáfora: o uso da anáfora nas relativas não preposicionadas ocorre quando a oração relativa é explicativa; quando o referente é + animado e, quando o valor semântico do conectivo oracional é de pessoa.

Quanto ao encaixamento social, não foi possível confirmar o que foi sinalizado por Corrêa (1998, p. 111) ao observar que o uso da anáfora é inibido pela escolaridade, já que esta variável não foi selecionada pelo programa nas rodadas. Isso pode ser justificado pelo fato de não haver polarização em Feira de Santana-BA, como constatado por Silva (2018, p. 219). Por fim, foi confirmada a hipótese do paradoxo do gênero proposto por Labov (2001, p. 278), já que as mulheres lideraram o uso da anáfora no português falado feirense. Em outras palavras, o sexo feminino foi mais inovador do que o sexo masculino frente à um fenômeno sem consciência social (LABOV, 2001, p. 278). Por fim, mesmo que as ocorrências tenham sido pouco expressivas, a quantificação permitiu análises interessantes quanto ao indício de uma possível e futura mudança linguística. 


\section{REFERÊNCIAS}

ALMEIDA, L. F. de. Urbanização, escolarização e variação linguística em Feira de Santana-Bahia (século XX). Tabuleiro de Letras: Revista do Programa de Pós-Graduação em Estudo de Linguagens, Universidade do Estado da Bahia - UNEB, Departamento de Ciências Humanas - DCH I, n. 04, jun. 2012, s/p.

ALMEIDA, N. L. F. de. O projeto A língua portuguesa no semiárido baiano - Fase 3: critérios de constituição e da amostragem do Banco de dados. In: FREITAG, R. M. Ko. (Org.). Metodologia de coleta e manipulação de dados em Sociolinguística. São Paulo: Edgard Blücher, 2014, p. 27-47.

BURGOS, E. Estratégias de Uso das Relativas em uma comunidade de fala afro-brasileira. 2003, $122 \mathrm{f}$. Dissertação (Mestrado em Letras e Linguística) - Instituto de Letras, Universidade Federal da Bahia, Salvador, 2003.

CORRÊA, V. R. Oração Relativa: O que se fala e o que se aprende no português do Brasil. 1998. Tese (Doutorado em Linguística) - UNICAMP, Campinas, 1998.

DUARTE, M. E. L. A perda do princípio "Evite Pronome" no português brasileiro. Tese (Doutorado), São Paulo: UNICAMP, 1995

DUARTE, M. E. L. A evolução na representação do sujeito pronominal em dois tempos. In: PAIVA, M. C. de e DUARTE, M. E. L. (org.) Mudança linguística em tempo real. Rio de janeiro: Contracapa/FAPERJ, 2003, p. 115-128.

GOMES, C. A. Variação e mudança na expressão do dativo no português brasileiro. In: PAIVA, M. C. de e DUARTE, M. E. L. (org.) Mudança linguística em tempo real. Rio de janeiro: Contracapa/FAPERJ, 2003, p. 81-96.

LABOV, W. Sociolinguistics patterns. 3. ed. Philadelphia: University of Pensylvania Press, 1972.

LABOV, W. Principles of Linguistic Change: social Factors. Oxford: Blackwell, 2001.

LUCCHESI, D. D. As duas grandes vertentes da história sociolingüística do Brasil (1500-2000), Revista D.E.L.T.A., São Paulo: v.17, n.1, p. 97-132, 2001. Disponível em: <http://www.scielo.br/pdf/delta/v17n1/a05v17n1.pdf>. Acesso em: 19 jun 2016.

LUCCHESI, D. Contato entre línguas e mudança linguística: as orações relativas no português afro-brasileiro. In: FIGUEIREDO, C. ARAÚJO, E. (Org.). Diálogos com Ribeiro: sobre gramáticas e história da língua portuguesa. Salvador: EDUFBA, 2015a, p. 77-119.

LUCCHESI, Dante. Língua e sociedade partidas: a polarização sociolinguística no Brasil. São Paulo: Contexto, 2015b, $320 \mathrm{p}$.

MATTOS E SILVA, R. V. Ensaios para uma sócio-história do português brasileiro. São Paulo: Parábola Editorial, 2004.

MOLLICA, M. C. Relativas em tempo real no português brasileiro contemporâneo. In: PAIVA, M. C. de e DUARTE, M. E. L. (org.) Mudança linguística em tempo real. Rio de janeiro: Contracapa/FAPERJ, 2003, p. 129-138.

OLIVEIRA, J.; RIBEIRO, I. Estratégias de relativização em atas de afro-brasileiros do século XIX. In: FIGUEIREDO, C. ARAÚJO, E. (Org.). Diálogos com Ribeiro: sobre gramáticas e história da língua portuguesa. Salvador: EDUFBA, 2015, p.149-173.

RIBEIRO, I. As sentenças relativas. In: LUCCHESI, D. (Org.). O português afro-brasileiro. Salvador: EDUFBA, 2009. p. 185-208.ROCHA LIMA, Carlos Henrique. Gramática normativa da língua portuguesa. 24. ed. Rio de Janeiro: José Olympio, 1984.

RIBEIRO, I.; FIGUEIREDO, C. Relativas. In: OLIVEIRA, K.. África à Vista: Dez estudos sobre o português escrito por africanos no Brasil do século XIX. Salvador: EDUFBA, 2009. p. 208-240. 
SILVA, J. C. Da. As orações relativas no português falado em Feira de Santana-BA. 2018, 240 f. Dissertação (Mestrado em Estudos Linguísticos), Feira de Santana: Universidade Estadual da Bahia, 2018.

TARALLO, Fernando. Diagnosticando uma gramática Brasileira: o português d'aquém e d'além-mar ao final do século XIX. In: ROBERTS, lan; KATO, Mary (orgs). Português Brasileiro: uma viagem diacrônica. 2. ed. Campinas: Editora da UNICAMP, 1993 (versão original em inglês 1991). p. 69-100.

TARALLO, F. L. Relativization strategies in brazilian portuguese. (Estratégias de relativização no português brasileiro). 1983. 273 f. Tese (Doutorado em Linguística), Pensilvânia: Universidade da Pensilvânia, 1983.

WEINREICH, U. LABOV, W. HERZOG, M. Fundamentos empíricos para uma teoria da mudança linguística. Tradução de Marcos Bagno; revisão técnica de Carlos Alberto Faraco; posfácio de Maria da Conceição Paiva e Maria Eugênia L. Duarte. São Paulo: Parábola, 2006. 